\title{
Towards Improved Lifespan for Wireless Sensor Networks: A Review of Energy Harvesting Technologies and Strategies
}

\author{
Souad Ehlali and Awatef Sayah
}

\begin{abstract}
Wireless Sensor Networks (WSN) have largely integrated all areas, including the military and civil fields. Their main limitation is their energy resources, which are very limited. Charging or replacing their batteries is often complicated or impossible, due to the high costs involved. The development of new approaches to energy management techniques for these autonomous systems has identified two strategic categories of energy management classification. The first category "Software" targets the development of algorithms for routing protocols to make transmissions smarter and more energyefficient. The second category "Hardware", focused more on new energy recovery technologies, has drawn the attention of academicians and industrialists because they bring a new manner of energy storage with life extension performance. Furthermore, this category has inspired new ways of supporting WSN administered applications such as real-time processes. In this paper, we review different current sources of Energy Harvesting Technologies and Strategies with WSN (EHTSWSN) and their various areas of applications. Our review provided a current analysis and future prospects for energy harvesting purposes in WSN. Hence, we propose that it would be required to ensure a compromise that combined the "Software" and "Hardware" designs of WSN in order to optimize energy consumption and therefore the lifetime of the network.
\end{abstract}

Keywords - EHTS-WSN, RF, Solar energy, Piezoelectricity, Wind energy.

\section{INTRODUCTION}

The need for the spatial and temporal availability of information is a forerunner of the developments in terms of Micro-Electro-Mechanical Systems (MEMS), wireless communication technologies, and embedded systems. This progress has led to the emergence of the WSN and subsequently to the Internet of Things (IoT). The high degree of interest in ubiquitous systems is justified by their very attractive specific features and their continuous innovation, which has allowed them to conquer various areas of implementation, leading to widely disparate applications.

The applications of WSN, whose objectives are fundamentally oriented towards autonomous and optimized tasks began like all advanced technologies, in the military field and then in civilian environments, such as industry, agriculture, health-medicine, home automation, smart building, or environmental monitoring. The WSN is in fact based on tiny wireless sensor nodes that are electronic devices based on embedded systems. The standard structure [1] of a sensor node is shown in Fig. 1. It is composed mainly of four basic units: the sensing unit, the processing unit MCU (Micro-Controller Unit), the communication unit, and the power unit or battery.

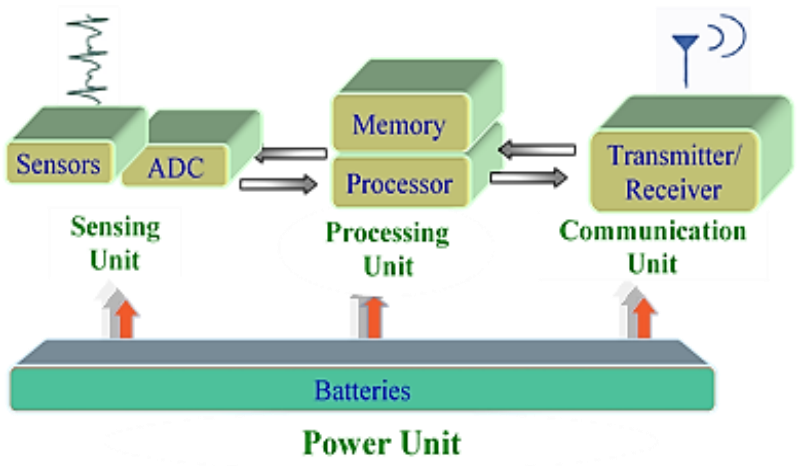

Fig. 1. Wireless sensor node structure model

WSN sensor nodes are deployed in very large numbers in various areas of interest. The major challenge of these networks is basically regarding the energy needed for their process, which is very limited. The problem is due to the fact that they are tiny and their energy capacities don't exceed a few joules, which makes their lifespan very limited.

In addition, loading or replacement of batteries is complicated, if not impossible due to the high cost that would be generated because of the great number of the deployed nodes for example, and also to, the significant footprint environment or the hostility environment where the network is deployed. Therefore, deeply studies and researches are needed to manage the energy provided by the batteries for the network nodes.

The research carried out for the new energy management methods, has led to classify two strategic categories for these autonomous systems. A category qualified as "Software" since it is oriented routing protocol algorithms [1]-[3] and in which the appropriate data traffic model is adopted, as well as short-range transmitting (IEEE.802.15.4, BLE "Bluetooth Low Energy", ...) or long-range transmitting (LoRa/LoRaWAN, SIGFOX compatible). This is in order to 
make transmissions smarter and more energy-efficient.

There is also a category called "Hardware" related to the material aspect like batteries (Alkaline, Lithium-ion, Ni-Cd, $\mathrm{Ni}-\mathrm{Mh}, \ldots$ ), supercapacitors (activated carbon, Manganese $(\mathrm{Mn})$, Graphite, ruthenium oxide $(\mathrm{RuO} 2)$, selected electrolyte, ...), dielectric materials, etc... In this category, we also find the new technologies of ambient energy recovery [4], [5], [6], [7], hence the appearance of another generation of Wireless Sensor Networks with Energy Recovery (WSNER). These new technologies have attracted academia and industry attention because they provide sufficient confidence in the operability of the network since, the ability to collect ambient energy allows a sustainable operation of the sensor nodes and therefore, of the network as well.

These are renewable energy collection technologies, which each had its own feature. One of the interesting contributions of this category is to support WSN-administered applications such as those used real-time processes and those that are used in the Internet of Things (IoT).

The rest of this review paper is arranged as follows: we analyzed and evaluated in Section II the importance of the combined architecture of rechargeable and non-rechargeable batteries in the WSN. Then, in Section III we describe some ambient energy sources achieving self-powered WSN and their fields of application. The interest of the collaboration between the development of routing protocols and energy harvesting technologies for energy efficiency in WSNs and in IoT is done in section IV. At last, the conclusion is presented in Section V.

\section{THE IMPORTANCE OF THE COMBINED ARCHITECTURE OF RECHARGEABLE AND NON-RECHARGEABLE BATTERIES}

The supply of electricity to the batteries of the WSN sensor nodes is a fundamental necessity. In general terms, electricity can be generated by supply and transmission systems from a variety of resources such as hydroelectric power and nuclear power, and also from off-grid systems such as solar, wind, radiofrequency, and others.

Regarding, the batteries of the WSN nodes, their electricity supply is nothing other than electrochemical storage resulting from electrochemical reactions. This leads, depending on the technologies adopted, to the production of several variants of rechargeable and non-rechargeable batteries. The lifespan of the WSN depends on the rate of the drainage of the energy of these batteries. The initial charge of these sensor nodes is limited and the batteries are small sized, hence the need to resort to other, complementary and/or alternative energy recovery resources. That could constitute an interesting compromise for the performance parameters.

The main approaches commonly adopted for the harvesting of energy from surrounding spaces are oriented along two axes:

- Recovery of ambient energy and consumption in realtime without any storage of energy: this management method is useful for the intermittent system between active and inactive states and whose operation is based exclusively on the energy recovered.

- Recovery of ambient energy and consumption in realtime with storage of the excess energy: This operation is more suitable since it incorporates batteries to save the energy collected in excess so that the system can remain operational even if, there is a power interruption from the ambient conditions.

Environmental energy recovery in WSN would be an effective solution to provide nodes power with rechargeable batteries for a variety of applications [26]. For sensor nodes, the size being small and the rate of energy consumption being is also low, the interest of this architecture combined rechargeable batteries and energy recovery system has a strong and promising potential for ensuring coverage, network connectivity, and durability of network operation.

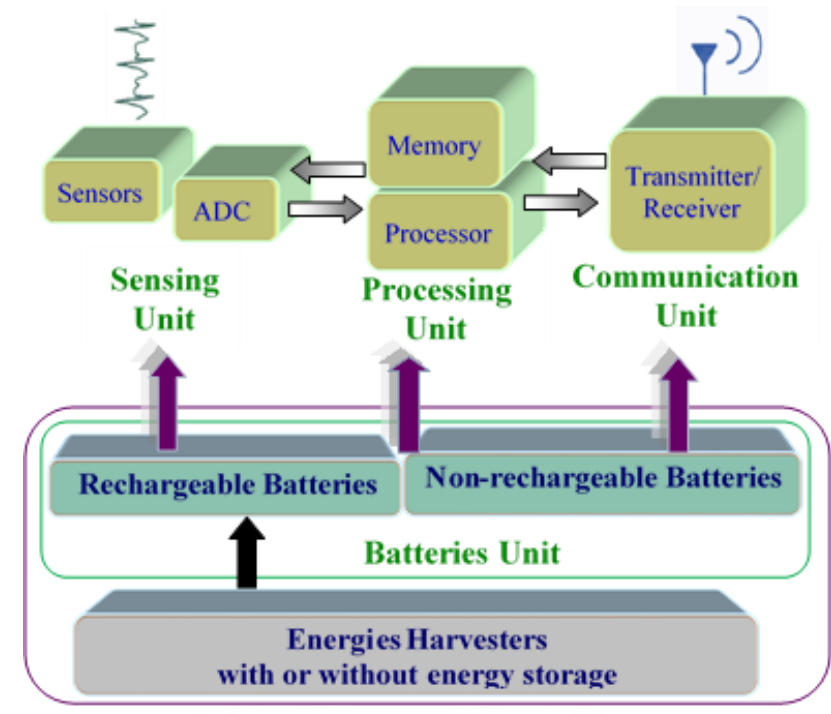

Power Management Unit

Fig. 2. The combining architecture of the power unit in the wireless sensor node.

It is an alternative with a double benefit, in terms of energy supply and also being an energy storage system. Fig. 2 shows a combined architecture of the energy power management unit of a wireless sensor node. This unit consists of two components:

- One component with two different types of batteries: with rechargeable batteries and another with nonrechargeable batteries

- A second component for the ambient energy recovery " Energies Harvesters"' with or without energy storage unit.

This is an efficient conceptual configuration for energy storage, which aims at both the collection of ambient energy and the wireless recharging of batteries in different forms and scales. This allows these systems to be equipped with integrated intelligence and achieve Energy Neutral Operation (ENO), which means that the energy available in a sensor node must be greater than or equal to the total energy it would consume.

These conditions improve the performance of WSN in terms of energy autonomy, quality of service, increase the monitoring time, the reliability and availability of the system and lead significantly to increasing the lifespan of the sensor nodes while attenuating the constraints imposed on physical maintenance of the network. 


\section{AMBIENT ENERGY SOURCES FOR THE WSN AND THEIR FIELDS OF APPLICATION}

Current energy requests are oriented towards the exploitation of ambient and renewable energy resources. In the WSN, this trend has developed amply to conquer a multitude of applications based on IoT. Researches in IoT Analytics shows the total number of device connections is continually growing. It displays the key role that these technologies can have on all aspects of our daily life, as well as the considerable benefit of these ambient energy sources that are becoming an increasingly obvious need.

There is a large variety of surrounding energy that would be harvested and converted into electrical energy. Fig. 4 shows different energy types and sources known at yet.

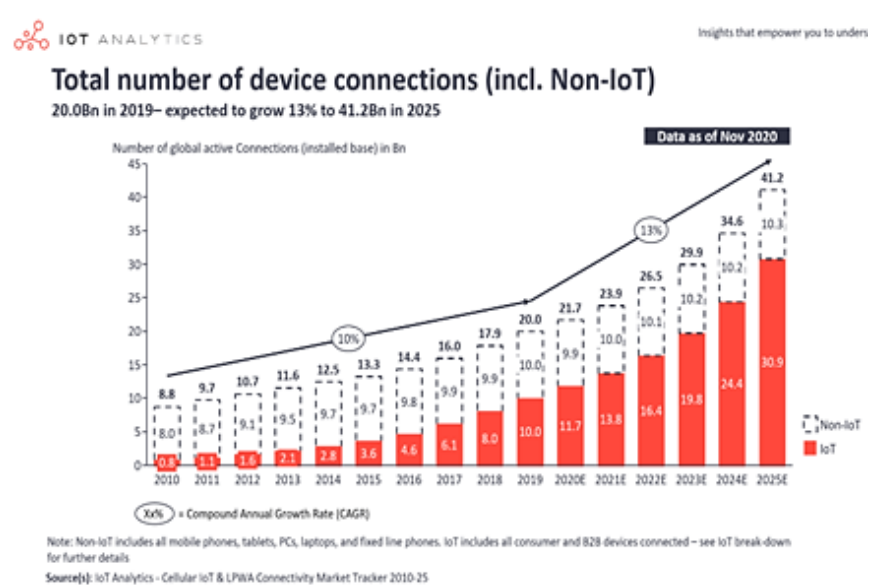

In the WSN sensor nodes, the batteries have a very limited lifespan, which does not allow them to align with the significant increase in energy consumption especially during data transmissions, which represent the maximum of energy expenditures in a sensor node. Fig. 5 shows how the evolution of the energy consumption is in a sensor node.

This inherent constraint has prompted the development of a multitude of alternative devices and technologies to ensure more energy autonomy. Among the proposals sought, we describe in this paper an extract from some energy sources used in the WSN, namely: Radio Frequency "RF" Energy Harvesting, Solar Energy Harvesting, Piezoelectricity Energy Harvesting and Wind Energy Harvesting.

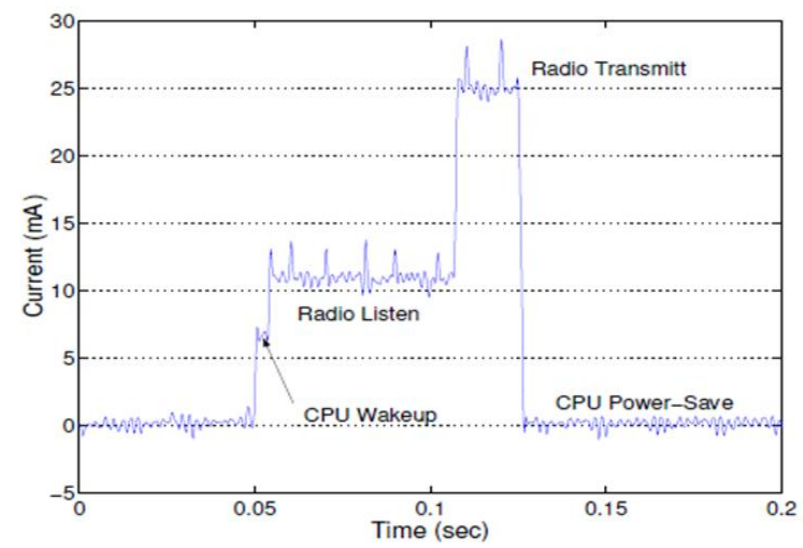

Fig. 5. Energy consumption in a sensor node [20].

Fig. 3. Total number of device connections [18]

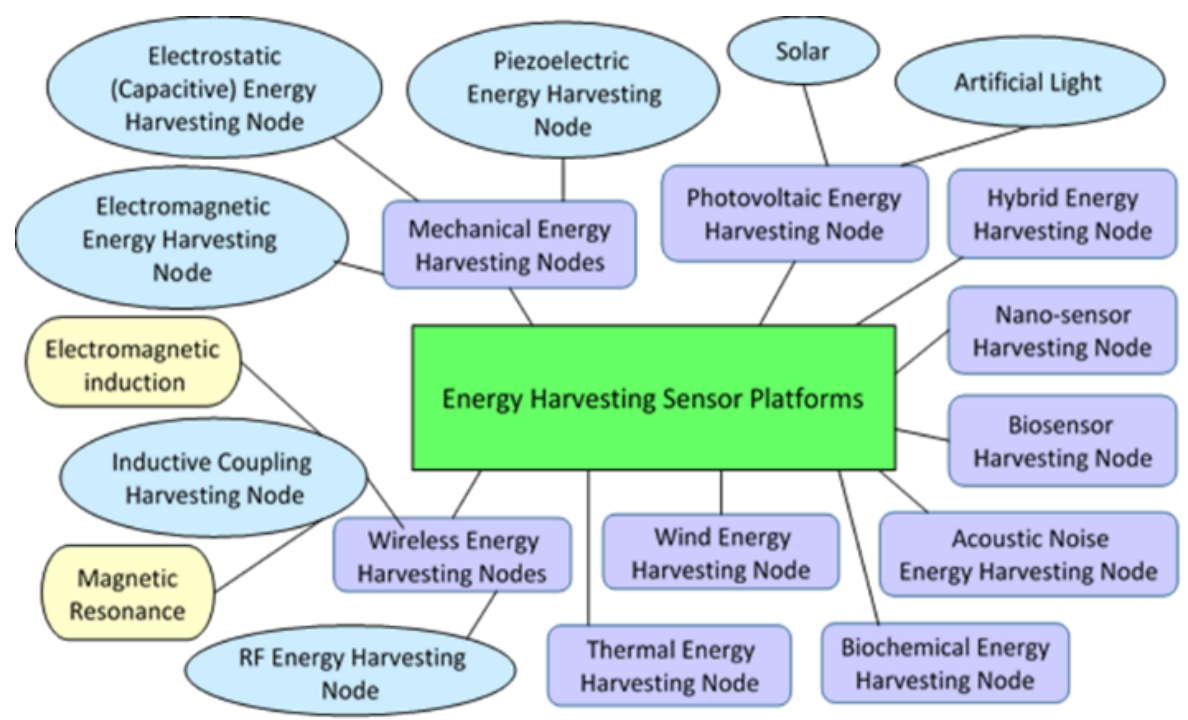

Fig. 4. Different energy types and sources [25].

\section{A. Radio Frequency " $R F$ " Energy Harvesting}

Radio Frequency (RF) Energy Harvesting is a mode of wireless energy transfer. These are ambient RF energy recovery systems, which exploit the energy sources already present in their environment [8]. These sources of ambient RF energy, are considered almost timeless despite their very low power density, path loss, shadowing, fading and RF-DC conversion efficiency [9]. They become increasingly highly valued, and continue to spread by the great expansion of telecommunications and broadcasting infrastructures. There are different approaches for harvesting ambient RF propagations from surrounding devices and emitting radio waves or electromagnetic waves [10], [11].

The highest power densities are, in particular, carried out in urban areas and near sources emitting radio waves such as base stations, cell phone towers or broadcasting towers. Fig. 6 illustrates a general representation of an RF-energy harvesting network: Infrastructure-based Architecture and Infrastructure-less Architecture.

In the infrastructure-based architecture there are three main components:

- The gateway, which is the base stations, wireless routers or relays; 
- The RF sources: can be RF energy transmitters or ambient RF sources;

- The sensor nodes that form the network and communicate data from their environment to the gateways.

Typically, power supplies to the gateways and the RF power sources are continuous and fixed. On the other hand, the nodes of the network recover energy from RF sources to ensure their functioning longer. In general, this aim is based on Wireless Power Transfer (WPT) technique to power up the sensor nodes.

In a decentralized structure, we have an infrastructure-less architecture. We are in RF energy recovery conditions where the network nodes communicate directly with each other (ad hoc) in the absence of a gateway. In Figure 6, the solid arrows represent the information flows, and the dotted arrows denote the energy flows.

These RF sources offer a very suitable means for recharging the nodes of sensors deployed in environments that don't tolerate the frequent replacement of batteries, in particular applications in a hostile environment or those dedicated to facilities reserved for medical monitoring.

\section{B. Solar Energy Harvesting}

Solar energy is radiant energy, which is the ambient energy most widely used, mainly due to its high availability, except in certain geographical regions with low solar potential, at night or during bad weather conditions. It has become more attractive [12], with a significant increase in the efficiency of photovoltaic cells in recent years [13]. The characteristic challenges of the WSN could not be supported by the old designs of these solar systems. On the other hand, currently, the use of solar energy in the WSN becomes increasingly privileged because of several advantages: energy conversion efficiency (close to $21 \%$ or up), easy integration and quick deployment. Table 1 shows a comparison of some photovoltaic cells used.

The solar cell's material (Monocrystalline, Polycrystalline, Amorphous ...) plays an important role in efficiency, form factor and cost. However, the cost of equipment and installation of photovoltaic cells and batteries is very high
[16]. Through the photovoltaic effect, and with minimal power loss, the circuit (designed for this type of source) converts light energy to produce the electricity necessary for the nodes. This is the production of constant direct current (DC), which does not require additional rectification for the conversion of alternating current (AC) into DC [4], [14], [27].

TABLE I: COMPARISON OF SOLAR CELLS [14]

\begin{tabular}{|c|c|c|c|}
\hline Solar Cell Type & Efficiency & Advantages & Disadvantages \\
\hline Monocrystalline & $15-24 \%$ & $\begin{array}{l}\text { High conversion } \\
\text { efficiency, the most } \\
\text { mature technology, } \\
\text { high reliability }\end{array}$ & $\begin{array}{l}\text { High cost, large } \\
\text { silicon } \\
\text { consumption, } \\
\text { complex } \\
\text { production } \\
\text { process } \\
\end{array}$ \\
\hline $\begin{array}{l}\text { Amorphous } \\
\text { silicon (a-Si) }\end{array}$ & $8-13.2 \%$ & $\begin{array}{l}\text { Low cost, easiness } \\
\text { of mass production, } \\
\text { relatively high } \\
\text { optical absorption } \\
\text { coefficient, very low } \\
\text { dark conductivity, } \\
\text { good response to } \\
\text { weak light }\end{array}$ & $\begin{array}{l}\text { Light-induced } \\
\text { recession effect, } \\
\text { low conversion } \\
\text { efficiency, low } \\
\text { stability }\end{array}$ \\
\hline $\begin{array}{c}\text { Cadmium } \\
\text { Telluride } \\
(\mathrm{CdTe})\end{array}$ & $\begin{array}{c}\text { Theoretical: } \\
28 \%\end{array}$ & $\begin{array}{l}\text { Ideal bandgap, high } \\
\text { light absorption rate, } \\
\text { high conversion } \\
\text { efficiency, stable } \\
\text { performance, simple } \\
\text { structure, low cost }\end{array}$ & $\begin{array}{l}\text { Limited natural } \\
\text { tellurium reserves, } \\
\text { high cost of } \\
\text { module and base } \\
\text { material, toxic } \\
\text { cadmium }\end{array}$ \\
\hline
\end{tabular}

The principle of this mechanism of solar energy recovery works with a harvesting capacity either at one or two levels (with or without energy storage) using batteries or supercapacitors. And that, in order to continue to use this source even outside the times of its instant availability.

Several WSN applications use solar energy to supply power to deploy nodes, in particular those designed for environmental supervision: monitoring the quality of air, water, forest fires, etc.

The Installation of photovoltaic cells in combination with the batteries of the sensor nodes in the WSNs contributes to increasing control, reliability and security while reducing the costs of maintaining the monitored systems.

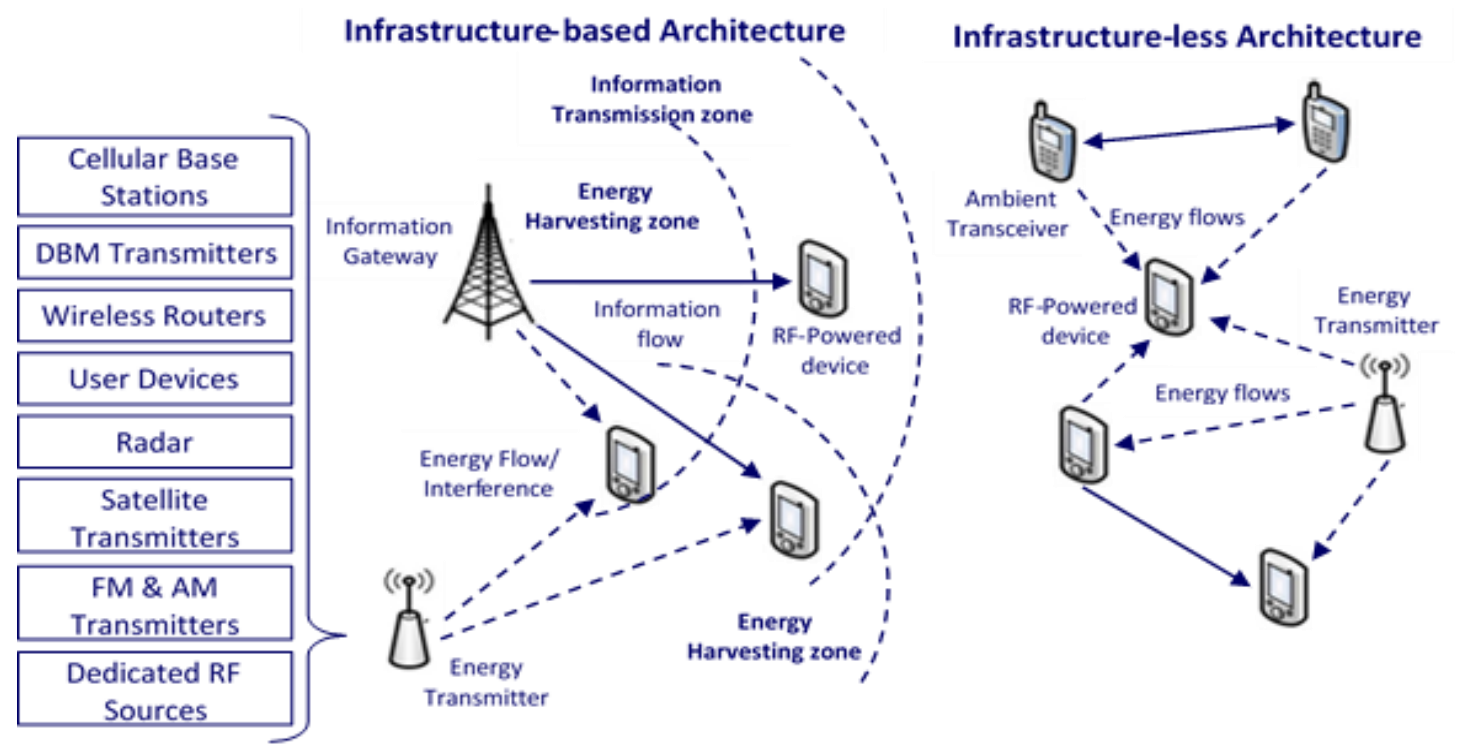

Fig. 6. General architecture of an RF energy harvesting network [10]. 


\section{Piezoelectric Energy Harvesting}

Several studies have been conducted on energy recovery and the autonomy of communicating systems like the WSN using piezoelectric converters [4]. The harvesting of piezoelectric energy is based on a phenomenon of conversion from mechanical energy into electrical energy by the polarization elements of the involved materials [19]. Through the properties of piezoelectric materials, the piezoelectric devices used to harvest energy, are able to generate energy at higher voltages without any external power supply. Mechanical energy can, for example, be oscillations, vibrations or human movements.

In WSN, even the issue to integrate piezoelectric devices into a small system, the piezoelectric devices are easy to design due to the absence of electromagnetic interference and their simple structure and low cost [14].

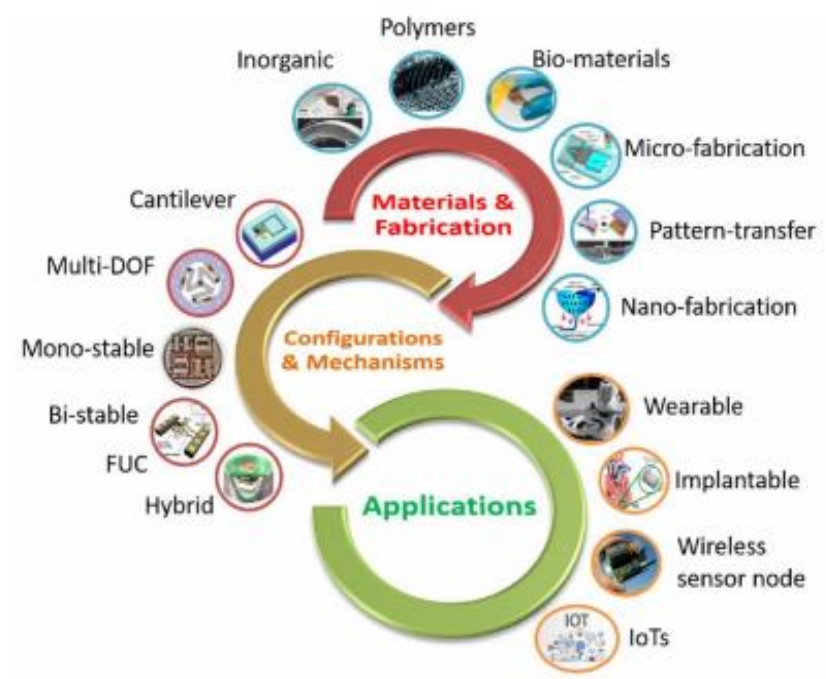

Fig. 7. A potential scheme of piezoelectric energy harvesting from materials to applications [28].

Fig. 7 below shows a potential scheme of piezoelectric energy harvesting consisting of materials, various harvesters, and prospective applications. The operating principle follows the impact due to an external force.

This resource is widely used in various fields [17]. For example, in health-medicine for harvesting the energy from heart-beats, in the industry for power supplying autonomous wireless sensors in monitoring and security systems, in agriculture for irrigation systems, in Underwater WSNs scheme (UWSNs), in Wireless Underground Sensor Networks (WUSNs) to communicate the geological data in real-time or also in animal tracking.

\section{Wind Energy Harvesting}

Wind flow is one of the oldest processes adapted to extract energy from natural resources such as air using hydroelectric turbines. The recovery of wind energy represents a form of complementary resource of energy, especially solar energy. For the WSNs, these are micro-turbines that operate in specific environments for energy production [24].

The main shortcoming of wind power is its non-continuous reliability [15]. In fact, the amount of energy harvested depends on the unpredictable behavior of the wind at all times.

Table II below is a rough comparison between some sources of ambient energy recovery.

TABLE II: COMPARISON OF MAXIMUM POWER DENSITY FROM ENERGY HARVESTING TECHNOLOGIES [25]

\begin{tabular}{|c|c|c|}
\hline $\begin{array}{c}\text { Energy harvesting } \\
\text { technique }\end{array}$ & Power density & Efficiency \\
\hline Photovoltaic & $\begin{array}{l}\text { Outdoors (direct sun): } \\
15 \mathrm{~mW} / \mathrm{cm}^{2} \\
\text { Outdoors (cloudy day): } \\
0.15 \mathrm{~mW} / \mathrm{cm} 2 \\
\text { Indoors: }<10 \mu \mathrm{W} / \mathrm{cm}^{2}\end{array}$ & $\begin{array}{c}\text { Highest: } \\
32 \pm 1.5 \% \\
\text { Typical: } 25 \\
\pm 1.5 \%\end{array}$ \\
\hline Thermoelectric & $\begin{array}{c}\text { Human: } 30 \mu \mathrm{W} / \mathrm{cm}^{2} \\
\text { Industrial: } 1 \text { to } 10 \mathrm{~mW} / \mathrm{cm}^{2}\end{array}$ & $\begin{array}{l} \pm 0.1 \% \\
\pm 3 \%\end{array}$ \\
\hline Pyroelectric & $\begin{array}{c}8.64 \mu \mathrm{W} / \mathrm{cm}^{2} \text { at the temperature } \\
\text { rate of } \\
8.5^{\circ} \mathrm{C} / \mathrm{s}\end{array}$ & $3.5 \%$ \\
\hline Piezoelectric & $\begin{array}{c}250 \mu \mathrm{W} / \mathrm{cm}^{3} \\
330 \mu \mathrm{W} / \mathrm{cm} 3 \text { (shoe inserts) }\end{array}$ & (a) \\
\hline Electromagnetic & $\begin{array}{c}\text { Human motion: } 1 \text { to } 4 \mu \mathrm{W} / \mathrm{cm}^{3} \\
\text { Industrial: } 306 \mu \mathrm{W} / \mathrm{cm}^{3} \text {, } \\
800 \mu \mathrm{W} / \mathrm{cm}^{3}\end{array}$ & (a) \\
\hline Electrostatic & 50 to $100 \mu \mathrm{W} / \mathrm{cm}^{3}$ & (a) \\
\hline RF & $\begin{array}{c}\text { GSM 900/1800 MHz: } \\
0.1 \mu \mathrm{W} / \mathrm{cm}^{2} \\
\text { WiFi } 2.4 \mathrm{GHz}: 0.01 \mu \mathrm{W} / \mathrm{cm}^{2}\end{array}$ & $50 \%(b)$ \\
\hline Wind & $380 \mu \mathrm{W} / \mathrm{cm}^{3}$ at the speed of $5 \mathrm{~m} / \mathrm{s}$ & $5 \%$ \\
\hline Acoustic noise & $\begin{array}{l}0.96 \mu \mathrm{W} / \mathrm{cm} 3 \text { at } 100 \mathrm{~dB} \\
0.003 \mu \mathrm{W} / \mathrm{cm} 3 \text { at } 75 \mathrm{~dB}\end{array}$ & (c) \\
\hline
\end{tabular}

- a): Maximum power and efficiency are source dependent.

- (b): Excluding transmission efficiency.

- (c): Noise power densities are theoretical values.

Energy recovery (EH) technology has a great potential to be an environmentally friendly solution that's why there are more specialized types of energy recovery from various sources [29].

\section{CONTRIBUTION OF DEVELOPMENT SOFTWARE IN THE OPTIMIZATION AND RECOVERY OF ENERGY IN THE WSN AND IN THE IOT}

As in many industrial applications, Wireless Sensor Networks (which is a very representative field in this context), are directly impacted by the mode of energy consumption management. Indeed, any exploitation without mastery of control leads directly to drifts in terms of cost, quality of operation, security, lifespan, etc.

It is therefore important to combine the Software solutions with the Hardware components mentioned above, to master the management of energy consumption and distribution in order to achieve the assigned objectives.

We know that the greatest amount of energy is required during the activity of the radio module in the data transmission (TX) and reception (RX) phases [8], [21], [22], [23]. This shows that in the operation of wireless sensor networks, the most important mechanism is manifested during data routing. Table III below displays in recent studies [23], the operating currents of fundamental electrical components of a sensor node. It shows that running during the communication mode (active mode) consumes over $80 \mathrm{~K}$ times more energy than in the sleep mode. 
TABLE III: WORKING CURRENTS OF TYPICAL ELECTRONIC COMPONENTS IN EMBEDDED DEVICES [23]

\begin{tabular}{cccc}
\hline \hline Module & Model & Current (active) & Current (sleep) \\
\hline \multirow{3}{*}{ RF chips } & CC2430 & $25 \mathrm{~mA}(\mathrm{TX})$ & $0.3 \mu \mathrm{A}$ \\
\cline { 2 - 4 } & CC2530 & $29 \mathrm{~mA}(\mathrm{TX})$ & $0.3 \mu \mathrm{A}$ \\
\cline { 2 - 4 } & AT86RF212 & $19 \mathrm{~mA}(\mathrm{TX})$ & $0.2 \mu \mathrm{A}$ \\
\hline MCU & MSP430 & $1.32 \mathrm{~mA}$ & $0.1 \mu \mathrm{A}$ \\
\hline $\begin{array}{r}\text { DC-DC } \\
\text { Converters }\end{array}$ & TPS8268x & $7 \mathrm{~mA}$ & $0.5 \mu \mathrm{A}$ \\
\cline { 2 - 4 } & LMZ10501 & $6.5 \mathrm{~mA}$ & $18 \mu \mathrm{A}$ \\
\hline \hline
\end{tabular}

Therefore, since, energy saving is a very relevant performance to extend the life of WSN, the development of an efficient routing protocol, is highly recommended for developing appropriate algorithms and techniques in terms of preservation energy. It is therefore obvious, that any routing protocol adopted will have to take into account the coexistence of several parameters and characteristics of the WSNs. We assign energy load balancing in the sensor nodes and more particularly the insurance of energy efficiency, the initial energy of nodes, the fault tolerance, the location of the base station, the scaling of coverage which is often very dense, etc.

Indeed, in our research [2], [3], for a new contribution in the process of raising awareness of energy conservation in WSN we achieved some prospections of the most used routing protocols. We were focused on the improvement of the most successful hierarchical routing protocols LEACH and PEGASIS.

Those protocols are based respectively on the clustering approach and the chain-forming approach, from which we designed and developed new algorithms CTEB "Clustering Technique based on Energy Balancing algorithm for routing in wireless sensor networks" [2] and ELMDGT "Efficient Lifetime Maximization Data Gathering Technique for routing in wireless sensor networks" [3]. Our new protocols allowed us to further optimize the energy consumption in WSN so that the system can last for more time. Fig. 8 shows a comparison between the developed CTEB protocol and LEACH protocol based on the number of still alive nodes vs transmission rounds until the first node is drained.

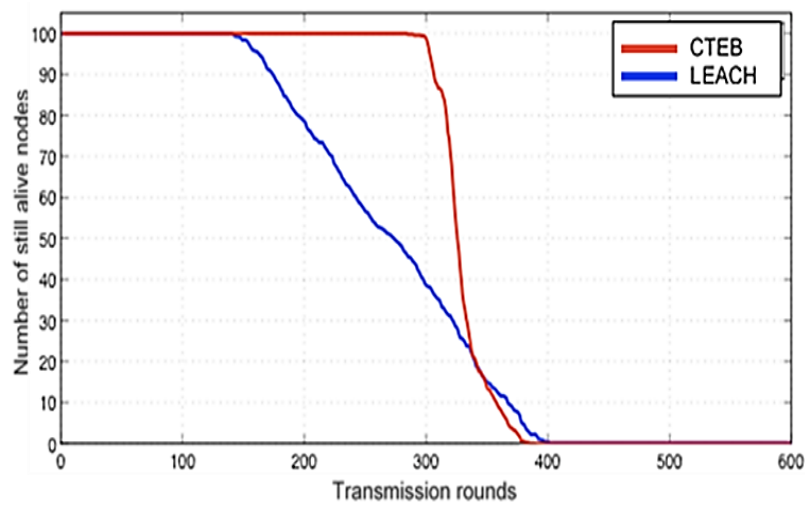

Fig. 8. Number of still alive nodes vs transmission rounds: A comparison between the developed CTEB and LEACH protocol until the first node is drained [2].

In Fig. 9 and Fig. 10 we can see the impact of choosing the appropriate algorithm on the conservation of batteries energy in the network and consequently on its lifespan.

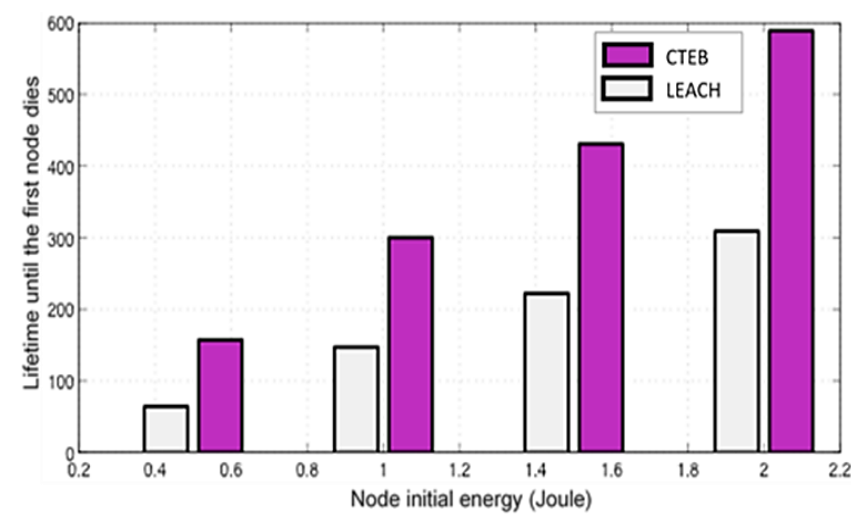

Fig. 9. Lifetime of the network until the first node dies vs Node initial energy (J): A comparison between the developed CTEB and LEACH protocol [2].

This was shown in Fig. 9 by making a comparison between the developed CTEB protocol and LEACH protocol on the behavior of the lifespan of the network based on the node initial energy until the first node dies.

The same assessment is shown in Fig. 10 between the developed ELMDGT protocol and LEACH protocol.

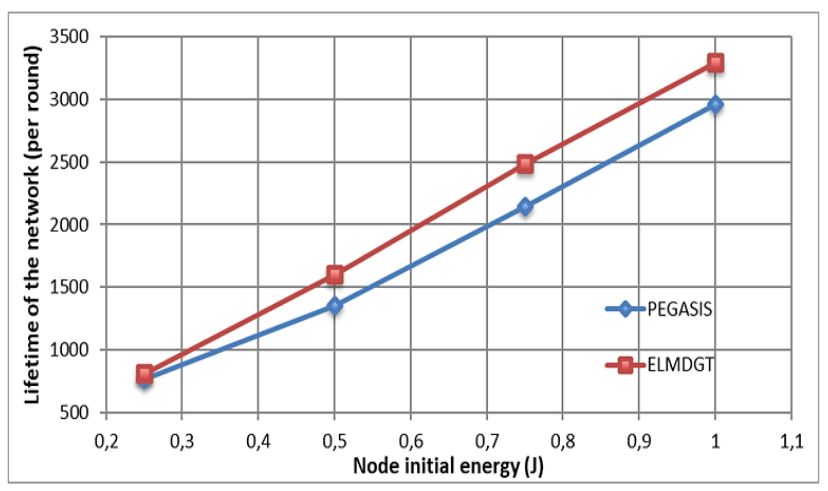

Fig. 10. Lifetime of the network until the first node dies vs Node initial energy (J): A comparison between the developed ELMDGT and LEACH protocol [3].

The solution of implementing advanced algorithms undoubtedly improves the optimization of energy consumption during the routing of data flows according to the conditions of their evolution.

With the development of digitalization technologies, advanced algorithms are developed as part of the concept of artificial intelligence. These algorithms are based on the collected data and the appropriate tools including big data, multivariable systems, machine learning, analytical methods, cognitive technology, experience scenarios, predictive models, neural networks, etc.

\section{CONCLUSION}

In the era of Industry 5.0, the WSN have a lot of potentials, particularly in the evolution of IoT, smart cities, etc. In fact, data collection is essential for several reasons, including security and prevention through the development of new designs for more robust risk management strategies, improvement of the quality of life and development of many smart systems.

The major challenge that we are led to take up for these tiny systems which form the WSN consists of knowing how 
these systems can become energetically autonomous and operate with an adequate level of safety. Also, the choice of the best energy to use depends on the nature of the application, its environment and the degree of objectives to be achieved. Therefore, unlimited potential energy supply can overcome the characteristic of having limited energy capacity, which may affect the efficiency of the system.

In this paper, we have highlighted the various current forms of renewable energy by emphasizing the interest in the recovery of ambient energy for the conservation of energy in wireless sensor networks.

From this reading, we propose the use of the combination of the "Software" and "Hardware" designs in the energy management of wireless sensor networks, which could undoubtedly lead to the optimization of the energy consumption and therefore the lifetime of the entire network.

In perspective, we motivate the approach relating to an intelligent energy cooperation scheme that allows multi-form energy recovery for wireless and battery-less sensor networks.

In this context, the way of using advanced algorithms for the choice of the method of energy management and distribution remains encouraging and makes it possible to reach the objectives in terms of reduction and optimization of energy consumption.

With the era of digitalization and the availability of ultrafast controllers, it is very promising to work approach to work closely with the concept based on big data, advanced algorithms and artificial intelligence solutions for serving energy management.

\section{REFERENCES}

[1] W.R. Heinzelman, A. Chandrakasan and H. Balakrishnan. An Application-Specific Protocol Architecture for Wireless Micro-sensor Networks. IEEE Transactions on Wireless Communications, December 2002;1(4): 660-670.

[2] S. Ehlali and A. Sayah. A Clustering Technique Based on Energy Balancing Algorithm for Routing in Wireless Sensor Networks. Journal of Theoretical and Applied Information Technology, April 2013;50(1): 51-56.

[3] S. Ehlali and A. Sayah. Efficient Lifetime Maximization Data Gathering Technique for Routing in Wireless Sensor Networks. Applied Mathematical Sciences, HIKARI, 2014; 8(28): 1381-1389.

[4] F. K. Shaikh and S. Zeadally, Energy Harvesting in Wireless Sensor Networks: A Comprehensive Review. Renewable and Sustainable Energy Reviews, 2016; 55: 1041-1054.

[5] S. Priya, H. C. Song, Y. Zhou, R. Varghese, A. Chopra, S.G. Kim, I Kanno, L. Wu, D.S. Ha and J. Ryu. A Review on Piezoelectric Energy Harvesting: Materials, Methods, and Circuits. Energy Harvesting and Systems, 2017; 4(1): 3-39.

[6] U. Baroudi. Management of RF Energy Harvesting: A Survey. Proceedings of the 16th International Multi-Conference on Systems, Signals \& Devices (SSD), pp. 44-49, Istanbul, Turkey, 2019.

[7] M. Bathre and P. K. Das, Hybrid Energy Harvesting for Maximizing Lifespan and Sustainability of Wireless Sensor Networks: A Comprehensive Review \& Proposed Systems. 2020 International Conference on Computational Intelligence for Smart Power System and Sustainable Energy (CISPSSE), pp. 1-6, Keonjhar, Odisha, India, 2020.

[8] H.H.R. Sherazi, L.A. Grieco and G. Boggia, A Comprehensive Review on Energy Harvesting MAC Protocols in WSNs: Challenges and Tradeoffs. Ad Hoc Networks, 2018; 71: 117-134.

[9] S. Kim, R. Vyas, J. Bito, K. Niotaki, A. Collado, A. Georgiadis and M.M. Tentzeris. Ambient RF Energy-Harvesting Technologies for Self-Sustainable Standalone Wireless Sensor Platforms. Proceedings of the IEEE, November 2014, pp. 1649-1666, Vol. 102, no. 11.

[10] X. Lu, P. Wang, D. Niyato, D. I. Kim and Z. Han. Wireless Networks with RF Energy Harvesting: A Contemporary Survey. IEEE
Communications Surveys \& Tutorials. Second quarter 2015; 17(2): 757-789

[11] K. N. Puniran, A. Robiah and R. A. Dziyauddin. RF Energy Harvesting with Multiple Sources and Co-Channel Interference Assisted. Journal of Advanced Research in Business and Management Studies. 2017; 8(2): 50-55.

[12] Y. Li and R. Shi. An Intelligent Solar Energy-Harvesting System for Wireless Sensor Networks. EURASIP Journal on Wireles. Communications and Networking, 2015; 179:1-12.

[13] Antony Saji M., S. Indu and R. Pandey. An Efficient Solar Energy Harvesting System for Wireless Sensor Network Nodes. Journal of Information and Optimization Sciences. 2020; 41(1): 39-50.

[14] G. Zhou, L. Huang, W. Li and Z. Zhu. Harvesting Ambient Environmental Energy for Wireless Sensor Networks: A Survey. Journal of Sensors. 2014; 1.

[15] M. Iqbal and F.U. Khan. Hybrid Vibration and Wind Energy Harvesting Using Combined Piezoelectric and Electromagnetic Conversion for Bridge Health Monitoring Applications. Energy Conversion and Management. 2018; 172: 611-618.

[16] O. Gulec, E. Haytaoglu and S. Tokat. A Novel Distributed CDS Algorithm for Extending Lifetime of WSNs With Solar Energy Harvester Nodes for Smart Agriculture Applications. IEEE Access 2020; 8:58859-58873.

[17] K. S Adu-Manu., N. Adam, C. Tapparello, H. Ayatollahi and W. Heinzelman, Energy-Harvesting Wireless Sensor Networks (EHWSNs): A Review. ACM Transactions on Sensor Networks, 2018 April; 14(2):1-50.

[18] Iot-analytics.com. State of the IoT 2020: 12 billion IoT connections, surpassing non-IoT for the first time, [Internet] 19 Nov. 2020 [update September 2021]. Available from: https://iot-analytics.com/state-ofthe-iot-2020-12-billion-iot-connections-surpassing-non-iot-for-thefirst-time.

[19] M. Xie, S. Dunn, E. Le Boulbar and C.R. Bowen. Pyroelectric Energy Harvesting for Water Splitting. International Journal of Hydrogen Energy. 2017; 42(37):23437-23445.

[20] V. Shnayder, M. Hempstead, B Chen., G. W. Allen and M. Welsh Simulating the Power Consumption of Large-Scale Sensor Network Applications. SenSys'04, 2004:188-200.

[21] V. Raghunathan, C. Schurgers, Sung Park and M. B. Srivastava, Energy-Aware Wireless Microsensor Networks. IEEE Signal Processing Magazine, 2002 March; 19(2): 40-50.

[22] E. Shih, S-H. Cho, N. Ickes, R. Min, A. Sinha, A. Wang, and A. Chandrakasan. Physical Layer Driven Protocol and Algorithm Design for Energy-Efficient Wireless Sensor Networks. Proceedings of the 7th annual international conference on Mobile computing and networking (MobiCom '01). Association for Computing Machinery, New York, USA, pp. 272-287. 2001.

[23] X. Ji, X. Zhou, M. Xu, W. Xu and Y. Dong, OPCIO: Optimizing Power Consumption for Embedded Devices via GPIO Configuration. ACM Transactions on Sensor Networks, 2020; 16.

[24] U. Raza and A. Salam. On-Site and External Energy Harvesting in Underground Wireless. Electronics, 2020;9(4): 681.

[25] S. Basagni, M.Y. Naderi, C. Petrioli and D. Spenza. Wireless Sensor Networks with Energy Harvesting. Mobile Ad Hoc Networking: The Cutting Edge Directions. John Wiley \& Sons Inc., Hoboken, NJ, 2013, Chapter 20, pp. 701-736.

[26] K. Z. Panatik, K. Kamardin, S. A. Shariff, S. S. Yuhaniz, N. A Ahmad,O M. Yusop, and S. Ismail. Energy Harvesting in Wireless Sensor Networks: A Survey. 2016 IEEE 3rd International Symposium on Telecommunication Technologies (ISTT). pp. 53-58. 2016.

[27] S. Thakur, D. Prasad and A. Verma, Energy Harvesting Methods in Wireless Sensor Network: A Review. International Journal of Computer Applications. 2017; 165(9):19-22.

[28] H. Liu, J. Zhong, C. Lee, SW. Lee and LN Lin. A Comprehensive Review on Piezoelectric Energy Harvesting Technology: Materials, Mechanisms and Applications. Applied Physics Reviews. 2018; 5(4):041306

[29] M. Grossi. Energy Harvesting Strategies for Wireless Sensor Networks and Mobile Devices: A Review. Electronics 2021, 10(661). 